\title{
Flexural Behaviour of Combined FA/GGBFS Geopolymer Concrete Beams after Exposure to Elevated Temperatures
}

\author{
Jun-ru Ren, Hui-guo Chen, Tao Sun, Hao Song, and Miao-shuo Wang \\ Department of Civil Engineering, Logistical Engineering University, Chongqing 401311, China \\ Correspondence should be addressed to Hui-guo Chen; chenhg_mail@163.com
}

Received 11 July 2017; Accepted 8 October 2017; Published 6 November 2017

Academic Editor: Prinya Chindaprasirt

Copyright (C) 2017 Jun-ru Ren et al. This is an open access article distributed under the Creative Commons Attribution License, which permits unrestricted use, distribution, and reproduction in any medium, provided the original work is properly cited.

As a promising alternative to OPC concrete, geopolymer concrete has been investigated and has demonstrated superior mechanical performance. Studying the thermal behaviour on the scale of a structural element is significant for introducing a new material to engineering applications. Four geopolymer concrete beams and four OPC concrete counterparts with the same reinforcement structure and similar concrete strength were subjected to three different heating cases at the rate of ISO834. The experimental results showed that the geopolymer concrete beams underwent a colour change, severe cracking, and no spalling after the exposure. While under load, the geopolymer concrete specimens exhibited a lower crack resistance and flexural stiffness. The residual load capacities were $110 \%, 107 \%$, and $90 \%$ of the ambient specimen for the geopolymer concrete samples and $103 \%$, $97 \%$, and $80 \%$ for the OPC concrete samples. To some extent, the geopolymer concrete beams achieved superior fire endurance compared to their OPC concrete counterparts.

\section{Introduction}

With the increasing awareness of emission reduction in all industries, geopolymer concrete (GC) has been seen as a promising alternative to ordinary Portland cement (OPC) concrete. Due to the use of industrial by-products, such as fly ash (FA), ground granulated blast furnace slag (GGBFS), metakaolin, and mine tailings, the carbon footprint emitted by the production of geopolymer cement is reported to be $80 \%-90 \%$ less than that of OPC [1]. These raw materials, which are abundant in aluminium and silicon, can easily dissolve in alkaline solution, breaking down to covalent $\mathrm{O}-\mathrm{Si}$ and $\mathrm{O}-\mathrm{Al}$ and eventually forming a Si-O-Al tetrahedral structure [2]. The reaction is called alkali activation or geopolymerization. Among the abovementioned synthesis precursors, FA and GGBFS wastes from electricity plants and iron works, respectively, have been found to be suitable for geopolymer cement. Both materials, which have huge annual productions, need no more calcinations than metakaolin and require less energy during fabrication. GGBFS was first employed as an additive to FA-based GC, which generally needs thermal curing to catalyse the reaction for better strength. Reports [35] showed that the addition of GGBFS with an angular shape not only enhanced its early-stage strength but also enabled it to attain a strength and workability similar to those of heatcured GC dominated by FA with a spherical shape at room temperature.

With decades of development, there have been numerous investigations, patents, and applications of GC [6], but the current use of this material in building construction is rare. The distinctive mechanical properties of GC have been extensively investigated in structural components, including beams, columns, panels, and pipes [7]. Sumajouw et al. [8, 9] pioneered and examined six underreinforced GC beams with various reinforcement ratios for flexural failure. The load capacities of another sixteen beams were also evaluated and compared to AS 3600 [10]. The results revealed that the flexural behaviours of GC specimens were similar to those of conventional cement concrete in terms of the effect of the reinforcement ratio on flexural capacity and the ductility index. Other investigations [11-15] also reported analogous performances of both types of beams in bending tests, such as first cracking load, crack width, load-deflection relationship, flexural stiffness, ultimate load, and failure mode. It was also reported that the capacities computed from AS 3600 [10], ACI 
TABLE 1: Chemical composition of FA and GGBFS (mass\%).

\begin{tabular}{lccccccccccc}
\hline Compounds & $\mathrm{SiO}_{2}$ & $\mathrm{Al}_{2} \mathrm{O}_{3}$ & $\mathrm{Fe}_{2} \mathrm{O}_{3}$ & $\mathrm{CaO}$ & $\mathrm{MgO}$ & $\mathrm{K}_{2} \mathrm{O}$ & $\mathrm{SO}_{3}$ & $\mathrm{TiO}_{2}$ & $\mathrm{P}_{2} \mathrm{O}_{5}$ & $\mathrm{Na}_{2} \mathrm{O}$ & $\mathrm{MnO}$ \\
\hline FA & 32.31 & 13.47 & 12.3 & 25.95 & 9.02 & 0.45 & 3.94 & 0.69 & 0.02 & 0.54 & 0.18 \\
GGBFS & 30.64 & 11.62 & 0.44 & 42.29 & 8.46 & 0.57 & 2.05 & 1.46 & 0.03 & 0.42 & 0.5 \\
\hline
\end{tabular}

318 [16], and IS 456 [17] were more conservative than the experimental results $[9,11,12]$. Hence, the existing codes were suitable for designing GC beams with conservative test-toprediction ratios. The GC beams were also shown to present an equal or higher shear capacity than that of OPC concrete beams [12]. All the articles above laid the foundation for the construction application of GC.

However, before putting any new building materials into practice, they should have a certain degree of fire resistance. Materials that lack fire resistance could lead to the catastrophic loss of life and property, especially if the impaired structure collapses. Due to the ceramic-like properties of geopolymer matrix, GC was widely believed to possess better fire resistance than OPC concrete $[18,19]$. Previous studies [20-22] investigated various systems of GC with respect to residual strength, as well as the mechanisms of deterioration on the macroscale and microscale. Though different types of raw materials might lead to contrasting thermal performance [18], an agreement on the three main causes of deterioration was reached: pore pressure, phase transformation [23], and incompatible deformation [21]. It was also proved in other geopolymer systems that the precursor type, specimen size [21], aggregate size [21], and heating regime [24] could affect the residual strength of GC. Limited studies [25, 26] highlighted the effects of high temperature on GGBFS/FA geopolymer materials. Guerrieri and Sanjayan [26] analysed the compressive strength of a combined FA and GGBFS geopolymer paste after exposure to $800^{\circ} \mathrm{C}$ with variables of mixture proportion, alkaline solution modulus, and sodium dosage. It was shown that the residual strength was influenced by the initial strength and that GC with a low initial strength would be enhanced by further hydration and sintering. Ren et al. [25] investigated the residual behaviour of FA/GGBFS GC subjected to different temperatures and cooling regimes. The weight change, strength loss, and ultrasonic characteristics were studied.

Despite the numerous works on GC in the shape of a cube or cylinder, the results cannot be translated into the thermal performance of larger specimens embedded with reinforcements. Likewise, though GC members behaved similarly to OPC concrete components in ambient conditions, the effects of elevated temperature and raw material type should be considered because of the distinct chemical reactivity and bulk matrix of the geopolymer binder. A study on the behaviour of damaged reinforced GC after elevated temperature exposure was not found. To the authors' knowledge, only Sarker and Mcbeath [27] examined the fire endurance of a FA-based GC panel. The report revealed that GC panels achieved less cracking, no spalling, and a higher residual load capacity than the OPC concrete counterparts. Furthermore, specimens in most works were subjected to a certain temperature, which did not mimic the actual conditions of a fire with a serious rate of increase in temperature.

In this research, four GC beams and four OPC concrete beams were fabricated and tested under a four-point flexural load after three diverse temperature exposures. The midspan deflection, crack development, and load capacity were examined and compared to those of OPC concrete beams. Each heating regime was controlled at the rate of ISO834 [28], the most widely adopted temperature curve for fires. The experimental data presented in this paper may assist in the application of GC to the sustainable development of infrastructure construction.

\section{Experimental Work}

2.1. Materials. Commercially available F class (low calcium) FA and normal GGBFS were prepared for GC specimens. GGBFS had a density of $2.9 \mathrm{~g} / \mathrm{cm}^{3}$ and a specific surface area of $470 \mathrm{~m}^{2} / \mathrm{kg}$. The chemical proportions of GGBFS and FA determined by XRF are tabulated in Table 1. Generalpurpose Portland cement was procured for OPC specimens. The alkaline activator utilized was a sodium silicate solution developed with an ordinary sodium silicate solution, sodium hydroxide flakes with $98 \%$ purity, and tap water. The modulus $\left(\mathrm{SiO}_{2} / \mathrm{Na}_{2} \mathrm{O}\right.$ by mass) of the sodium silicate solution was $3.13\left(\mathrm{SiO}_{2}=25.72 \%, \mathrm{Na}_{2} \mathrm{O}=8.48 \%\right.$, and water $\left.=65.8 \%\right)$. Aggregates, including fine aggregates and coarse aggregates, were employed in the SSD condition. The coarse aggregates were crushed limestone from a local quarry with a size of $5-35 \mathrm{~mm}$, and the fine aggregates were river sand with a fineness modulus of 2.58. The reinforcement of every beam was normal ductility deformed bars.

2.2. Mixture Proportions. It was noted that the moisture content and the modulus of the alkaline activator would affect the workability and strength of GC $[29,30]$. Based on many trial experiments, the modulus and the water content of the alkaline activator were adjusted to 1.8 and $73 \%$, respectively, by adding extra $\mathrm{NaOH}$ and water. The $\mathrm{NaOH}$ solution was prepared one day prior to casting. The mixture proportions of GC and OPC concrete are provided in Tables 2 and 3. The initial strength of both concretes and reinforcement is given in Figure 6.

2.3. Specimen Preparation. Four GC beams, four OPC concrete beams, and the corresponding heating cases are listed in Table 4. As shown in Figure 1, the same size, same reinforcement design, and similar concrete strengths were controlled for a credible comparison. The reinforcement ratio of the longitudinal tensile bars was $1.6 \%\left(A_{s}=628 \mathrm{~mm}^{2}, h_{0}=\right.$ $257 \mathrm{~mm}$ ), indicating an underreinforced design. The stirrups were placed along the shear span in case of shear failure. 

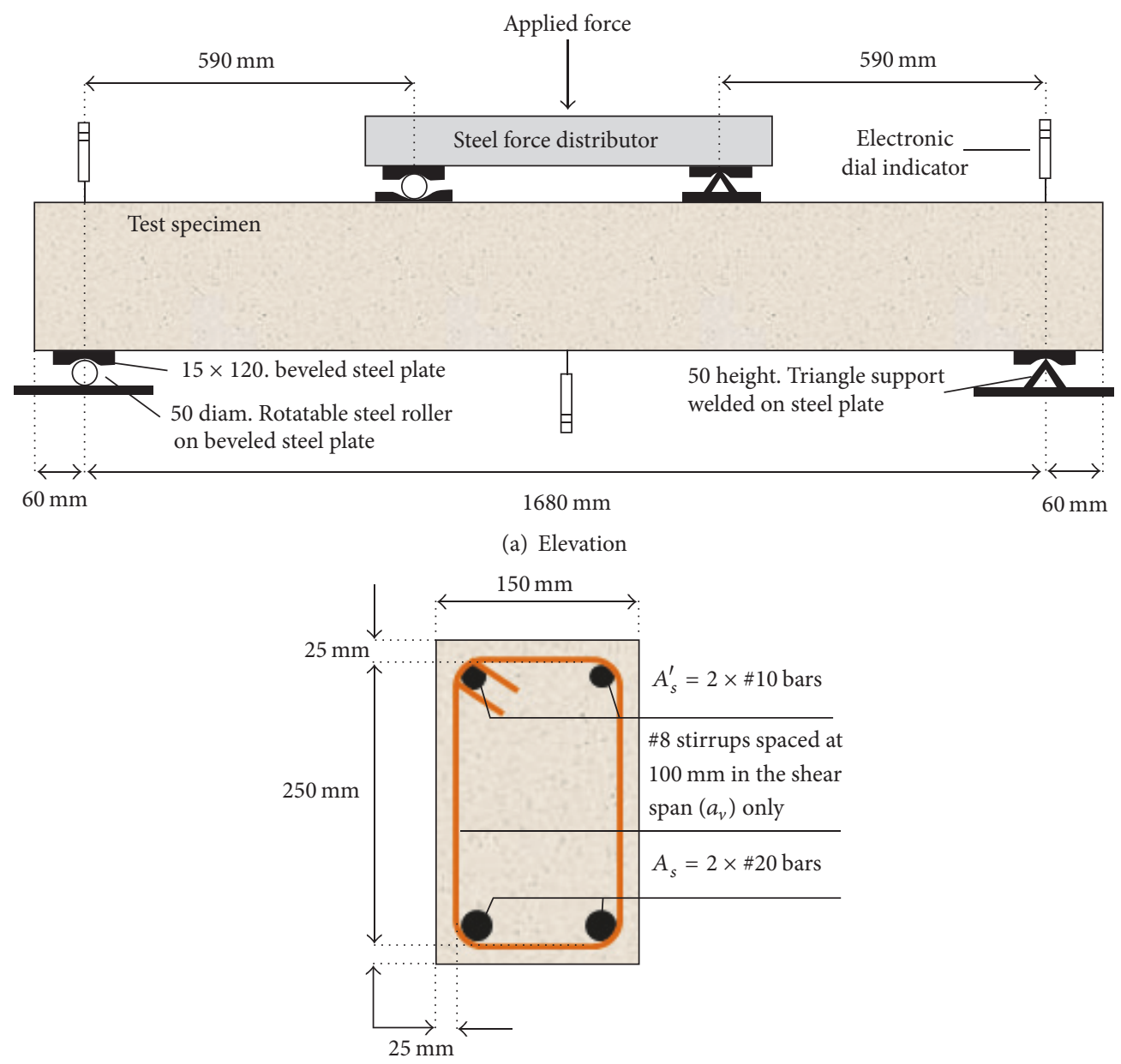

(b) Cross section

FIgUre 1: Test sample details.

TABLE 2: Geopolymer concrete mixture composition $\left(\mathrm{kg} / \mathrm{m}^{3}\right)$.

\begin{tabular}{lcccccc}
\hline GGBFS & FA & Sand & Coarse aggregates & Sodium silicate & $\begin{array}{c}\text { Alkaline activator } \\
\text { Sodium hydroxide }\end{array}$ \\
\hline 140 & 210 & 644 & 1196 & 134 & 11 & Water \\
\hline
\end{tabular}

Reinforcement-structured and wooden moulds were fabricated onsite. GC and OPC concrete were mixed in a span mixer with a power of $4 \mathrm{~kW}$. The manufacturing procedure of geopolymer specimens was as follows: (1) blend the GGBFS, FA, and fine aggregates for $2 \mathrm{~min}$; (2) add coarse aggregates and dry-mix them for another $1 \mathrm{~min}$; (3) add alkaline activator and mix it for a final $1 \mathrm{~min}$; and (4) pour the mixture into the moulds and compact them with an electric vibrator. The specimens were demoulded $1 \mathrm{~d}$ after casting, sprayed with water, and covered with plastic film for $30 \mathrm{~d}$ for the ambient curing. Before the thermal exposure, the specimens were put in a cool and dry place to reach SSD. Three concrete cubes and two $500 \mathrm{~mm}$ samples of tensile rebar were derived from each specimen.

2.4. Heating Regime. Three heating treatments were used in this work: Case (I) $400^{\circ} \mathrm{C}$ for $1 \mathrm{~h}$; Case (II) $600^{\circ} \mathrm{C}$ for $1 \mathrm{~h}$;
TABLE 3: OPC concrete mixture composition $\left(\mathrm{kg} / \mathrm{m}^{3}\right)$.

\begin{tabular}{|c|c|c|c|c|c|}
\hline Cemen & Sand & Coarse aggregates & Water & $\mathrm{W} / \mathrm{C}$ ratio & Sand ratio \\
\hline 488 & 599 & 1163 & 200 & 0.41 & 34 \\
\hline
\end{tabular}

and Case (III) $600^{\circ} \mathrm{C}$ for $2 \mathrm{~h}$. ISO834 [28] was employed to simulate the temperature in an actual fire. A gas furnace was used to calcinate the specimens. It had a two-clamshell structure insulated by high alumina fibre blankets with one thermocouple and four burners equipped on each shell. The specimens were placed upside down onto the insulation to create a three-face burning scenario. The furnace could be automatically operated using stored programmes. When the temperature reached the target, the furnace would automatically hold for the scheduled time and then cut off the gas to let the specimens cool to room temperature inside. The 
TABLE 4

\begin{tabular}{lccc}
\hline Material & Heating case & Temperature & Sample ID \\
\hline \multirow{3}{*}{ Geopolymer } & - & Ambient & GB-A \\
concrete & (I) & $400^{\circ} \mathrm{C}$ & GB-4 \\
& (II) & $600^{\circ} \mathrm{C}-1 \mathrm{~h}$ & GB-6 \\
& (III) & $600^{\circ} \mathrm{C}-2 \mathrm{~h}$ & GB-6-2 \\
\hline \multirow{2}{*}{ OPC concrete } & - & Ambient & OB-A \\
& (I) & $400^{\circ} \mathrm{C}$ & OB-4 \\
& (II) & $600^{\circ} \mathrm{C}-1 \mathrm{~h}$ & OB-6 \\
& (III) & $600^{\circ} \mathrm{C}-2 \mathrm{~h}$ & OB-6-2 \\
\hline
\end{tabular}

reserved samples were heated in the corresponding heating case simultaneously (see Figures 2 and 3 ).

2.5. Loading Regime. As shown in Figure 1, the specimens were under four-point load through a steel force distributor. The force was implemented by an electrohydraulic servo testing system (HONGSHAN China) with a maximum load of $500 \mathrm{kN}$ which can also automatically record the loads. A preload of $5 \mathrm{kN}$ was applied to detect the possible disorder of instruments and ensure contact between every component. After zero setting, step loading was operated. $20 \mathrm{kN}$ and $10 \mathrm{kN}$ load for each step were used before and after the yielding of reinforcement, respectively. The load in each step was held for $5 \mathrm{~min}$ and all measurements were recorded before and after the holding duration.

\subsection{Measuring Method}

2.6.1. Deflection. To measure the actual mid-span deflection, avoiding the influence of the support settlement, three electronic dial indicators were placed to gauge the deflection and the support settlement separately. At the beginning and end of the load holding duration, all data were manually recorded.

2.6.2. Cracks. The temperature cracks were traced on the specimens with a marker pen after thermal exposure. During the load holding, the opening and spacing of stressed cracks were likewise traced. The widths of the main cracks were detected twice at the beginning and end of the hold duration using a reading microscope at the position of the longitudinal steel bar. For safety, the data near the failure of the beam were not measured.

\section{Results and Discussion}

3.1. Physical Observation. Both specimen types underwent qualitative changes, including a colour change and temperature cracking, after being subjected to an elevated temperature. The colour of the GC specimens turned to dark grey, light grey, and pink in the three heating cases, respectively. However, the colour of each specimen was nonuniform, which might have resulted from the air motion in the furnace and the location of each specimen. Some beams also locally became orange, which was ascribed to the high iron content of FA that induced a kinetic ferrihydrite-hematite phase

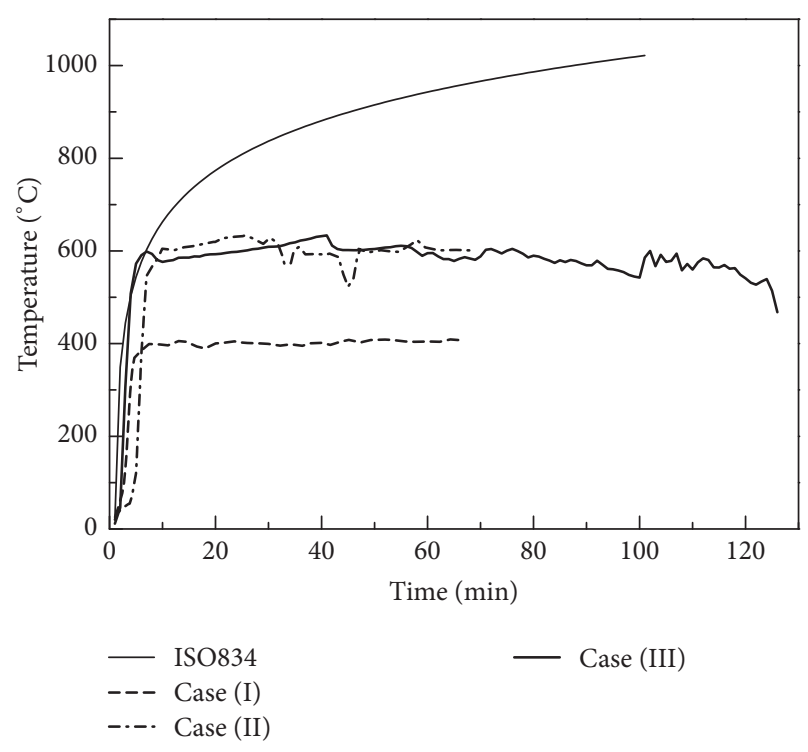

Figure 2: Temperature curves.

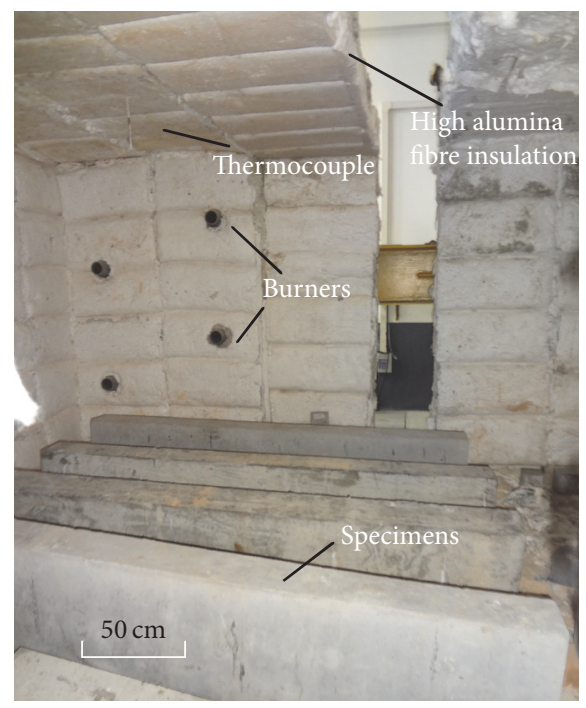

Figure 3: Gas furnace.

change [31]. Comparatively, the colour changes of the GC specimens were more obvious, which could reflect the degree of damage to the structures.

The thermal cracking was affected by pore pressure, thermal deformation, and phase change of geopolymer. The steam pressure caused the initial cracks. However, the shrinkage of geopolymer and corresponding incompatible deformation with coarse aggregates were primary causes because when aggregates expanded in high temperature, the geopolymer exhibited evident shrinkage [20, 22, 23]. Meanwhile, the dehydroxylation and dehydration were typical and dominant phase changes of FA geopolymer at around $600^{\circ} \mathrm{C}$, which also led to shrinkage.

Temperature-induced crack nets covered each specimen, and their area and width developed progressively with the heating regimes. The distribution of the temperature cracks 


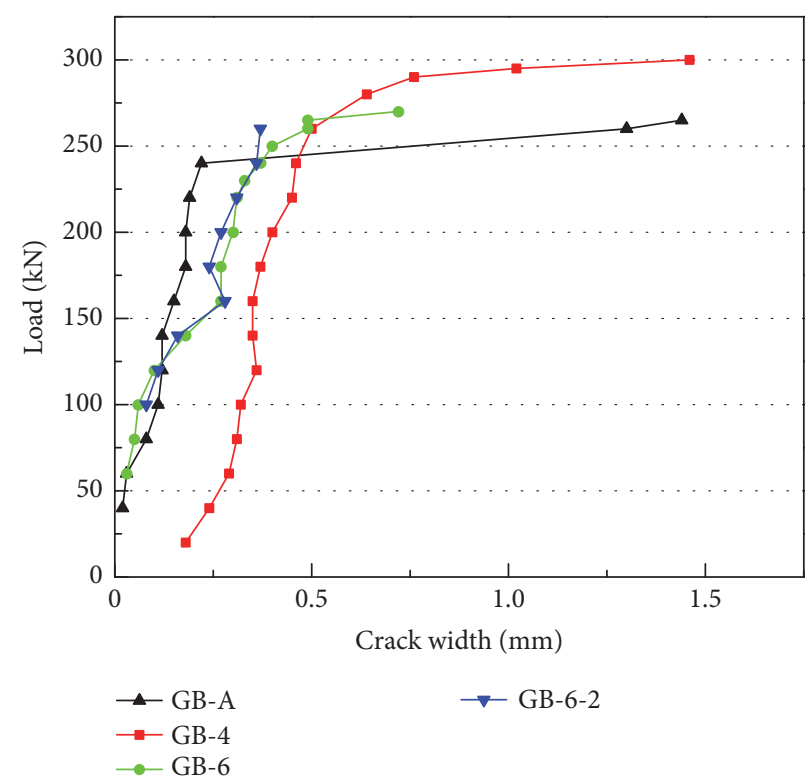

(a) Geopolymer concrete specimens

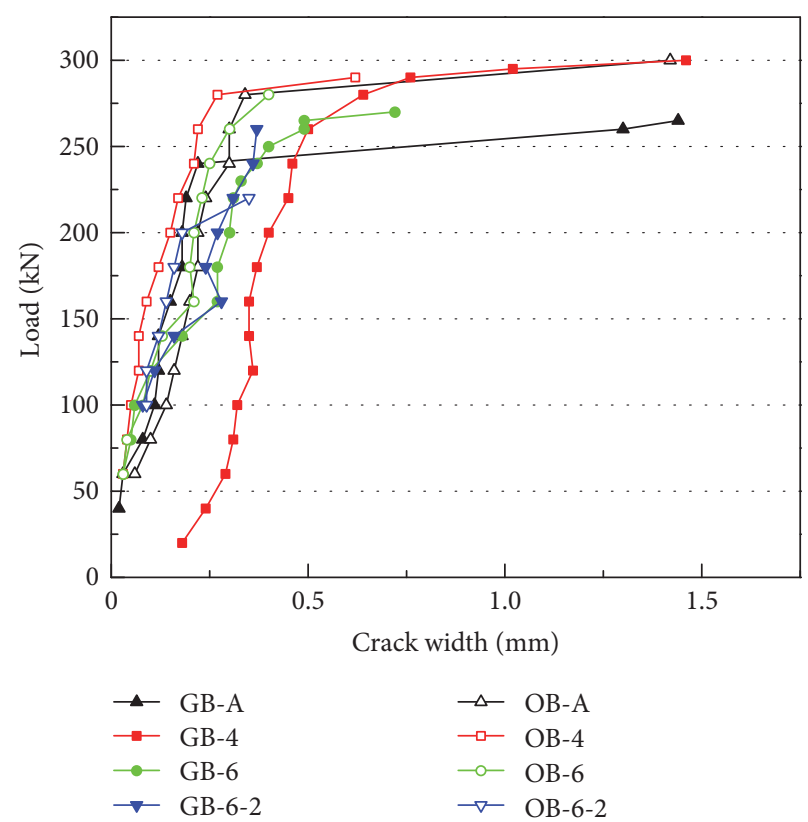

(b) Comparison

FIGURE 4: Load-crack width curves.

of both types of specimens was also nonuniform along the length and height. Most cracks began at the top of the specimen, which was not directly get burnt, and then spread to the bottom, where fewer cracks opened. This might have been caused by the asymmetric reinforcement structure, where the thicker ribbed steel bars at the bottom provided more powerful constraints.

In comparison, the temperature cracks of the GC specimens were more crucial than those of the OPC concrete specimens, which were more intense and wider. It was reported that the shrinkage of the geopolymer binder was more substantial than that of the OPC paste, especially when $\mathrm{Na}_{2} \mathrm{SiO}_{3}$ was used as the alkaline activator [32]; the binder also demonstrated sharp shrinkage at high temperatures [22, 33]. On the other hand, the observation contradicted the results in [27] that GC cracked less, which might be attributed to the distinctive type of geopolymer system. It is worth noting that more pores and no spalling phenomena were observed in the GC specimens.

3.2. Cracks. The initiation and propagation of cracks indicate the ability of structural members to serve as such. In addition to the temperature cracks, flexural cracks and shear cracks formed under load. The width of the failure crack of each specimen is provided in Figure 4. The bearing cracks generally developed along the temperature cracks with the load energy dissipated among them. This led to curl cracks, making it difficult to trace the cracks of some specimens, such as GB-6-2, until failure. As the temperature increased, the cracks propagated faster, the height of which decreased, foreboding an overreinforced failure.

The GC beams cracked faster than the OPC concrete beams. The flexural cracks almost emerged in the first load step, and all appeared in the second or third load step; one or two of these cracks developed to failure cracks. The shear cracks initiated later but became wider and more intense than the flexural cracks, the latter indicating the pronounced deterioration in shear capacity. One GC specimen experienced shear failure, and the phenomenon did not fit the description in [12] that GC beams acquired an equal or higher shear capacity.

As shown in Figure 4(a), there was no distinct regularity in the crack width with varying heating cases. The exposed specimens developed wider cracks than the ambient samples, and GB-4 developed the widest cracks. The curves were concentrated with a similar trend under a lower load $(<150 \mathrm{kN})$ and then dispersed as the load increased. The appearance and extension of the crack span revealed the plasticity of the GC beams. After the yielding of the reinforcements, the width of GB-A and GB-4 rose quickly with a slight increase of load showing an improvement in capacity and a clear portent of failure. However, the spans of GB-6 and GB-62 were not detected, and they collapsed abruptly during the load-sustained period.

It is revealed in Figure 4(b) that the cases with a gradual change in temperature equally had little impact on the crack width of the OPC concrete beams. The exposed specimens even developed narrower cracks than the ambient ones. Comparatively, the GC specimens displayed wider cracks than the OPC concrete specimens under the same load. The inferior crack resistance was not in agreement with former research showing that GC had a residual tensile strength higher than that of the OPC concrete. This might be attributed to the compounded effects of multiple factors, such as the bond properties and material type. 


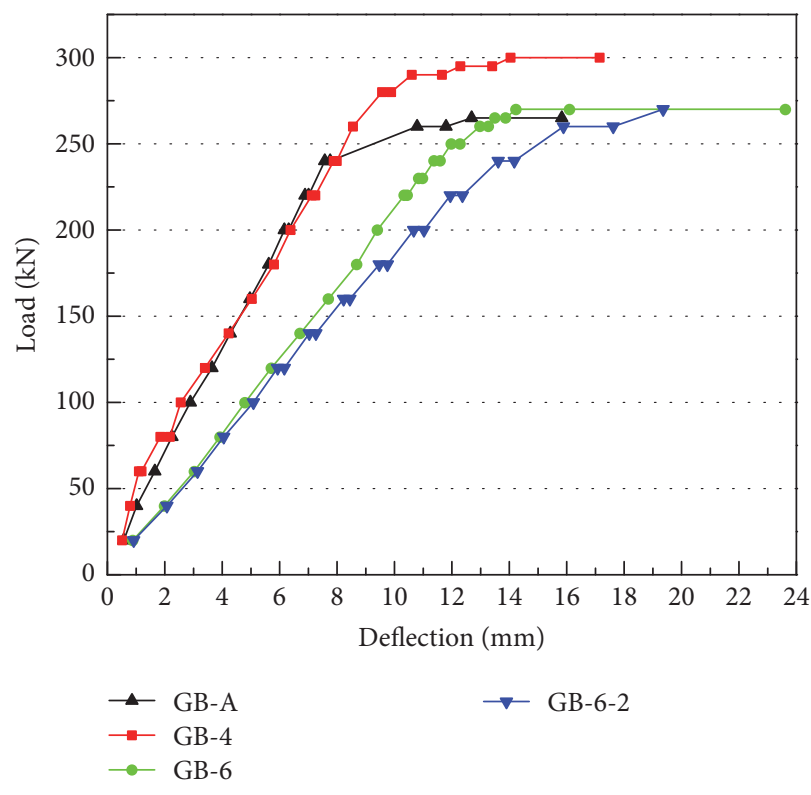

(a) Geopolymer concrete specimen

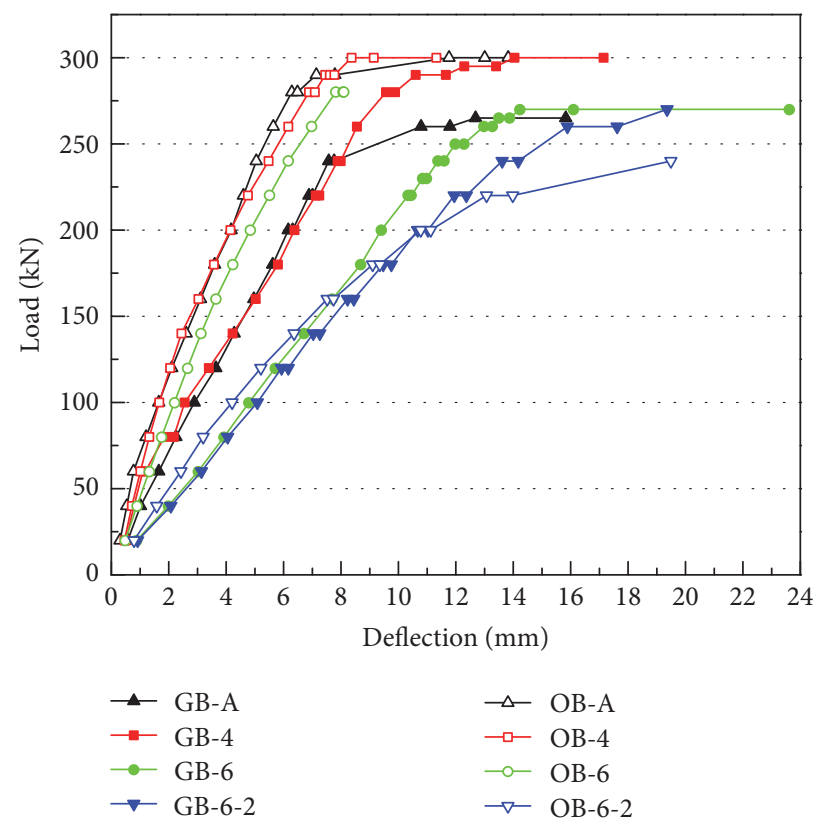

(b) Comparison

Figure 5: Load-deflection curves.

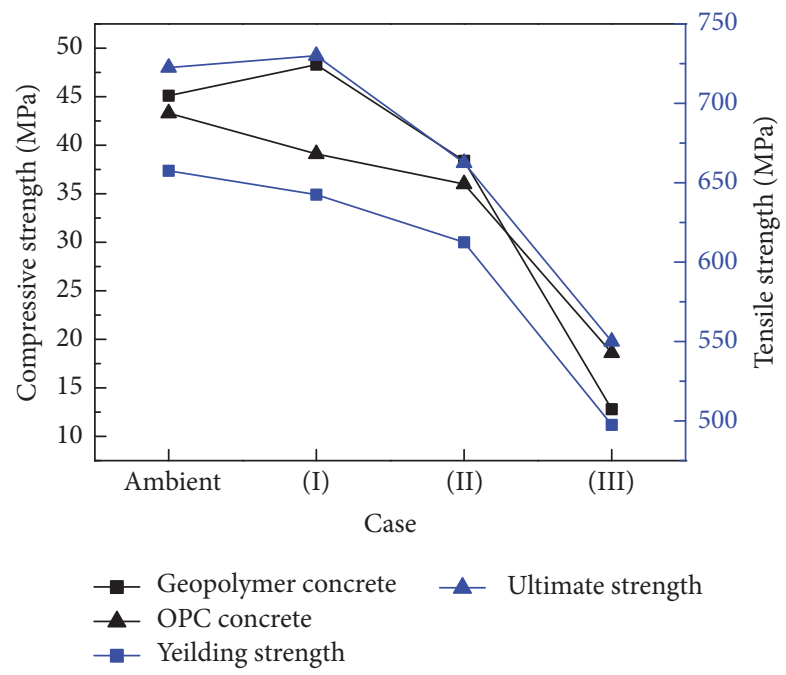

FIGURE 6: Strength of reserved concrete and reinforcement.

3.3. Load-Deflection Results. Defection could imply some mechanical changes to the beams, such as local buckling, local cracking, and reinforcement slippage. As shown in Figure 5(a), the two-stage curves of the GC specimens included the inelastic stage with cracks, the slope of which reflected the stiffness, and the plastic stage, which presented the ductility and bearing capacity. The GB-4 curve corresponded approximately to that of GB-A and even overtook the latter in the second stage, demonstrating a higher capacity, while the slope noted a slight reduction in stiffness. GB-6 and GB-6-2 displayed similar load capacities. However, the smaller slope and the shorter plateau of GB-6-2 indicated an evident decrease in stiffness and plastic deformation. As shown in Figure 5(b), the OPC concrete specimens gained a positively gradual reduction in bearing capacity and bending stiffness upon thermal exposure. This was especially true for OB-6-2, which achieved the smallest capacity and stiffness. It should be noted that the plateau stage was not detected for OB-6 and OB-6-2, which suddenly failed in the loadkeeping period without conspicuous plastic deformation. Comparatively, the curves of GC specimens were below the curves of the OPC concrete specimens, indicating the smaller flexural stiffness of the GC specimens after being subjected to elevated temperatures.

3.4. Load Capacity and Failure Mode. The failure mode of each specimen was determined through the crack and deflection results, along with field observation. The pronounced increases in crack width and deflection were considered to be the marks of reinforcement yielding, and the yielding load was correspondingly recorded; the ultimate load was recorded automatically by the testing system.

The ambient specimen GB-A presented the typical failure of an underreinforced beam under bending. From the yielding of the steel bar to the crush of compressive concrete, the capacity improved with a sharp increase in deflection, and the width of the cracks clearly indicated the following collapse with proper ductility. Nonetheless, the yielding features of the exposed specimens, such as GB-4 and GB-6, were not prominent, and the increment of capacity also decreased. Some beams broke down without reinforcement yielding, such as GB-6-2, which gained a slight increase in crack width and deflection, along with shorter cracks, before failure. The collapse of GB-6-2 started from the stratiform cracks on the mid-span upper concrete and was followed by the heaving 


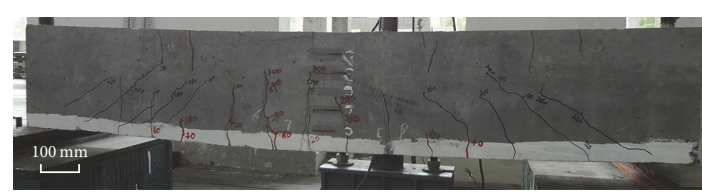

(a) GB-4

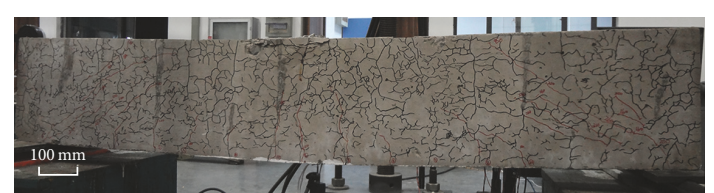

(b) GB-6-2

FIGURE 7: Failure of GC beams.

TABLE 5: Flexural bearing capacity of simply supported beams.

\begin{tabular}{lccc}
\hline ID & $P_{\mathrm{y}} / \mathrm{kN}$ & $P_{\mathrm{u}} / \mathrm{kN}$ & \multicolumn{2}{c}{ Reduction ratio/\% } \\
\hline Type & \multicolumn{3}{c}{ Geopolymer concrete } \\
\hline GB-A & 250 & 268 & - \\
GB-4 & 270 & 300 & +11 \\
GB-6 & 255 & 270 & +0.7 \\
GB-6-2 & - & 265 & -1 \\
\hline Type & & OPC concrete \\
\hline OB-A & 285 & 301 & - \\
OB-4 & 295 & 310 & +3 \\
OB-6 & 285 & 291 & -3 \\
OB-6-2 & - & 240 & -20 \\
\hline
\end{tabular}

and crush of concrete, conspicuous characteristics of an overreinforced failure.

The evolution of the specimens' capacities and damage patterns was closely connected to the residual strength of the concrete and reinforcement after being exposed to elevated temperatures. As shown in Figure 6, the residual strength of GC was higher than that of the OPC concrete, which lost more strength for the same case. Furthermore, GC was characterized by the strength gain behaviour observed in Case (I). For the reinforcements, a shaper reduction in tensile strength occurred after thermal exposure at $600^{\circ} \mathrm{C}$. It was reported in $[34,35]$ that the basic properties of steel bars could recover after being exposed to temperatures lower than $600^{\circ} \mathrm{C}$.

Table 5 provides the yielding capacity $\left(P_{\mathrm{y}}\right)$, ultimate capacity $\left(P_{\mathrm{u}}\right)$, and the reduction ratio to the ambient specimen. GB-4 obtained a remarkable improvement in yielding and ultimate capacity that was mainly attributable to the strengthening behaviour of GC. The enhancement of GC after temperature exposure was commonly reported in [18, $33,36,37]$ that the alkali activation of the remnant precursors induced by ambient curing was catalysed by the high temperature when free water was not liberated. The augmentation of GC predominated over the damage brought about by vapor pressure and thermal incompatibility. Meanwhile, the deterioration of the rebar was relatively slight, and it was concluded that GB-4 achieved the net result of a higher capacity.

In other cases, $600^{\circ} \mathrm{C}$ was the critical temperature for GC [25]. The geopolymerization terminated because of the loss of moisture, while the geopolymer matrix was still complete [33, $38,39]$. The main reasons for the decrease in cubic strength might be the thermal incompatibility between the binder and aggregates [22], which regularly amounts to between
$65 \%$ and $80 \%$. It was revealed in some studies [20, 22, 23] that while coarse aggregates progressively expanded at elevated temperatures, geopolymer binders experienced notable shrinkage. Furthermore, dehydration and dehydroxylation could be somewhat responsible for the reduction of strength [37]. However, on a larger scale, GB-6 had a similar capacity to GB-A. Because of the nonuniform temperature field of the specimen, the outer concrete began to lose strength while the inner part was strengthened. In addition, with the sharper decrease of tensile strength for the rebars, GB-6 did not have an improvement in capacity. Contributing to the weakest GC and steel bars, GB-6-2 achieved the lowest capacity without rebar yielding, demonstrating the characteristics of overreinforced failure.

GC beams under a flexural load resembled the mechanical performance and changing behaviour of the OPC concrete beams. The OPC specimens had a relatively obvious decline in capacity. From the angle of the bearing capacity, the GC beams had better fire resistance (see Figure 7).

\section{Conclusion}

The geopolymer concrete beams after exposure to elevated temperatures experienced clear colour changes and temperature cracks, which evolved with the aggravation of heating conditions. The temperature cracks were more intense and wider than those of the OPC concrete beams. The evident features after fire exposure could be utilized to appraise the extent of the fire damage of geopolymer concrete structures. Under loads, the geopolymer concrete specimens cracked earlier, developed more shear cracks, and exhibited lower flexural stiffness than the OPC concrete counterparts. With a similar failure mode to the OPC concrete beams, the geopolymer concrete beams achieved a higher capacity in Case (I) and retained more load capacity in the other heating cases.

The structural performance of geopolymer concrete after being subjected to elevated temperature was influenced by multiple factors, and the material demonstrated some defects; this was inconsistent to the behaviour of the ambient beams and the behaviour described in former research. Further investigations should be conducted to analyse the temperature field and bond behaviour, as well as to improve the crack resistance and flexural stiffness of GC for possible applications.

\section{Conflicts of Interest}

The authors declare that they have no conflicts of interest. 


\section{Acknowledgments}

This work was supported by the Chongqing Science and Technology Commission, Chongqing, China [cstc2016jcyjA0569].

\section{References}

[1] P. Duxson, J. L. Provis, G. C. Lukey, and J. S. J. V. Deventer, "The role of inorganic polymer technology in the development of green concrete," Cement \& Concrete Research, vol. 37, no. 12, pp. 1590-1597, 2007.

[2] J. Davidovits, "Geopolymers: inorganic polymeric new materials," Journal of Thermal Analysis and Calorimetry, vol. 37, no. 8, pp. 1633-1656, 1991.

[3] S. Kumar, R. Kumar, and S. P. Mehrotra, "Influence of granulated blast furnace slag on the reaction, structure and properties of fly ash based geopolymer," Journal of Materials Science, vol. 45, no. 3, pp. 607-615, 2010.

[4] P. S. Deb, P. Nath, and P. K. Sarker, "The effects of ground granulated blast-furnace slag blending with fly ash and activator content on the workability and strength properties of geopolymer concrete cured at ambient temperature," Materials \& Design, vol. 62, pp. 32-39, 2014.

[5] Z. Li and S. Liu, "Influence of slag as additive on compressive strength of fly ash-based geopolymer," Journal of Materials in Civil Engineering, vol. 19, no. 6, pp. 470-474, 2007.

[6] P. J. Davidovits, "30 years of Successes and Failures in Geopolymer Applications," Market Trends and Potential Breakthroughs, 2002.

[7] K. H. Mo, U. J. Alengaram, and M. Z. Jumaat, "Structural performance of reinforced geopolymer concrete members: A review," Construction and Building Materials, vol. 120, pp. 251264, 2016.

[8] M. J. Sumajouw, D. Hardjito, S. E. Wallah et al., "Behavior and strength of reinforced fly ash-based geopolymer concrete beams," Civil Engineering Dimension, vol. 6, no. 2, 2005.

[9] D. M. J. Sumajouw, "Low-calcium fly ash-based geopolymer concrete: reinforced beams and columns," Research Report GC, Curtin University of Technology, Perth, Australia, 2006.

[10] Australian Standard AS 3600, Concrete Structures, Standards Australia, Sydney, 2004.

[11] J. K. Dattatreya, N. P. Rajamane, D. Sabitha, P. S. Ambily, and M. C. Nataraja, "Flexural behaviour of reinforced geopolymer concrete beams," International Journal for Computational Civil \& Structural Engineering, vol. 2, no. 1, pp. 138-159, 2011.

[12] J. R. Yost, A. Radlińska, S. Ernst, M. Salera, and N. J. Martignetti, "Structural behavior of alkali activated fly ash concrete. Part .Structural testing and experimental findings," Materials and Structures/Materiaux et Constructions, vol. 46, no. 3, pp. 449462, 2013.

[13] S. Kumaravel and S. Thirugnanasambandam, "Flexural behaviour of reinforced low calcium fly ash based geopolymer concrete beams," Global Journal of Researches in Engineering, vol. 13, no. 8, pp. 177-180, 2013.

[14] S. Kumaravel, S. Thirugnanasambandamm, and C. A. Jeyasehar, "Flexural Behaviour of Geopolymer Concrete Beams with GGBS," IUP Journal of Structuring Engineering, vol. 7, no. 1, pp. 45-54, 2014.

[15] W. Yodsudjai, "Application of fly ash-based geopolymer for structural member and repair materials," Advances in Science \& Technology, vol. 92, pp. 74-83, 2014.
[16] ACI Committee 318, Building Code Requirements for Structural Concrete (ACI 318-02), American Concrete Institute, Farmington Hills, Mich, USA, 2002.

[17] IS: 456-2000, Indian Standard. Plain and Reinforced Concrete - Code of Practice, New Delhi, India, 2000.

[18] D. L. Y. Kong, J. G. Sanjayan, and K. Sagoe-Crentsil, "Comparative performance of geopolymers made with metakaolin and fly ash after exposure to elevated temperatures," Cement \& Concrete Research, vol. 37, no. 12, pp. 1583-1589, 2007.

[19] D. L. Y. Kong, J. G. Sanjayan, and K. Sagoe-Crentsil, "Factors affecting the performance of metakaolin geopolymers exposed to elevated temperatures," Journal of Materials Science, vol. 43, no. 3, pp. 824-831, 2008.

[20] D. L. Y. Kong and J. G. Sanjayan, "Damage behavior of geopolymer composites exposed to elevated temperatures," Cement \& Concrete Composites, vol. 30, no. 10, pp. 986-991, 2008.

[21] D. L. Y. Kong and J. G. Sanjayan, "Effect of elevated temperatures on geopolymer paste, mortar and concrete," Cement \& Concrete Research, vol. 40, no. 2, pp. 334-339, 2010.

[22] Z. Pan, J. G. Sanjayan, and D. L. Y. Kong, "Effect of aggregate size on spalling of geopolymer and Portland cement concretes subjected to elevated temperatures," Construction \& Building Materials, vol. 36, no. 36, pp. 365-372, 2012.

[23] A. V. Riessen, W. Rickard, and J. Sanjayan, "15 - Thermal properties of geopolymers," Geopolymers, vol. 40, no. 9, pp. 315-342, 2009.

[24] A. Diouri, M. Talha Junaid, A. Khennane et al., "Investigation into the effect of the duration of exposure on the behaviour of GPC at elevated temperatures," in Proceedings of the MATEC Web of Conferences 11, vol. 11, article 01003, April 2014, 10.1051/ matecconf $/ 01003$.

[25] W. Ren, J. Xu, and E. Bai, "Strength and ultrasonic characteristics of alkali-activated fly ash-slag geopolymer concrete after exposure to elevated temperatures," Journal of Materials in Civil Engineering, vol. 28, no. 2, article 04015124, 2016.

[26] M. Guerrieri and J. G. Sanjayan, "Behavior of combined fly ash/slag-based geopolymers when exposed to high temperatures," Fire and Materials, vol. 34, no. 4, pp. 163-175, 2010.

[27] P. K. Sarker and S. Mcbeath, "Fire endurance of steel reinforced fly ash geopolymer concrete elements," Construction \& Building Materials, vol. 90, pp. 91-98, 2015.

[28] International Standards Organisation, Fire Resistance Tests, Elements of Building Construction (ISO 834), Switzerland; 1980.

[29] P. S. Deb, P. Nath, and P. K. Sarker, "The effects of ground granulated blast-furnace slag blending with fly ash and activator content on the workability and strength properties of geopolymer concrete cured at ambient temperature," Materials \& Design, vol. 62, pp. 32-39, 1980.

[30] X.-H. Yuan, Y. Yan, Z.-A. Lu, and L.-M. Yu, "Hydration process study on the alkali-activated slag cementing materials," Journal of Chemical and Pharmaceutical Research, vol. 6, no. 4, pp. 11801184, 2014.

[31] W. D. A. Rickard, A. Van Riessen, and P. Walls, "Thermal character of geopolymers synthesized from class F Fly ash containing high concentrations of iron and $\alpha$-quartz," International Journal of Applied Ceramic Technology, vol. 7, no. 1, pp. 81-88, 2010.

[32] C. Shi, P. V. Krivenko, and D. Roy, Alkali-Activated Cements and Concretes, Taylor \& Francis, New York, NY, USA, 2006. 
[33] Z. Pan, J. G. Sanjayan, and F. Collins, "Effect of transient creep on compressive strength of geopolymer concrete for elevated temperature exposure," Cement \& Concrete Research, vol. 56, no. 2, pp. 182-189, 2013.

[34] W.-Z. Zheng, M.-X. Xu, and Y. Wang, "Fire resistance behavior of reinforced concrete and prestressed concrete materials," Harbin Jianzhu Daxue Xuebao/Journal of Harbin University of Civil Engineering and Architecture, vol. 35, no. 4, pp. 6-10, 2002.

[35] Z. Guo, Mechanical Properties of Concrete And Strucltural Elements in Ambient and High Temperature, Tsinghua University Press, Tsinghua, China, 2006.

[36] T. W. Cheng and J. P. Chiu, "Fire-resistant geopolymer produce by granulated blast furnace slag," Minerals Engineering, vol. 16, no. 3, pp. 205-210, 2003.

[37] O. A. Abdulkareem, A. M. M. A. Bakri, H. Kamarudin, I. K. Nizar, and A. E. A. Saif, "Effects of elevated temperatures on the thermal behavior and mechanical performance of fly ash geopolymer paste, mortar and lightweight concrete," Construction \& Building Materials, vol. 50, suppl. 1, pp. 377-387, 2014.

[38] Z. Wang, J. Xu, and W. Ren, "Damage evolution and dynamic constitutive model of geopolymeric concrete at elevated temperature," Journal of Vibration \& Shock, vol. 35, no. 2, pp. 110-115, 2016.

[39] P. Duxson, G. C. Lukey, and J. S. J. van Deventer, "Thermal evolution of metakaolin geopolymers: Part 1 - Physical evolution," Journal of Non-Crystalline Solids, vol. 352, no. 52-54, pp. 55415555, 2006. 

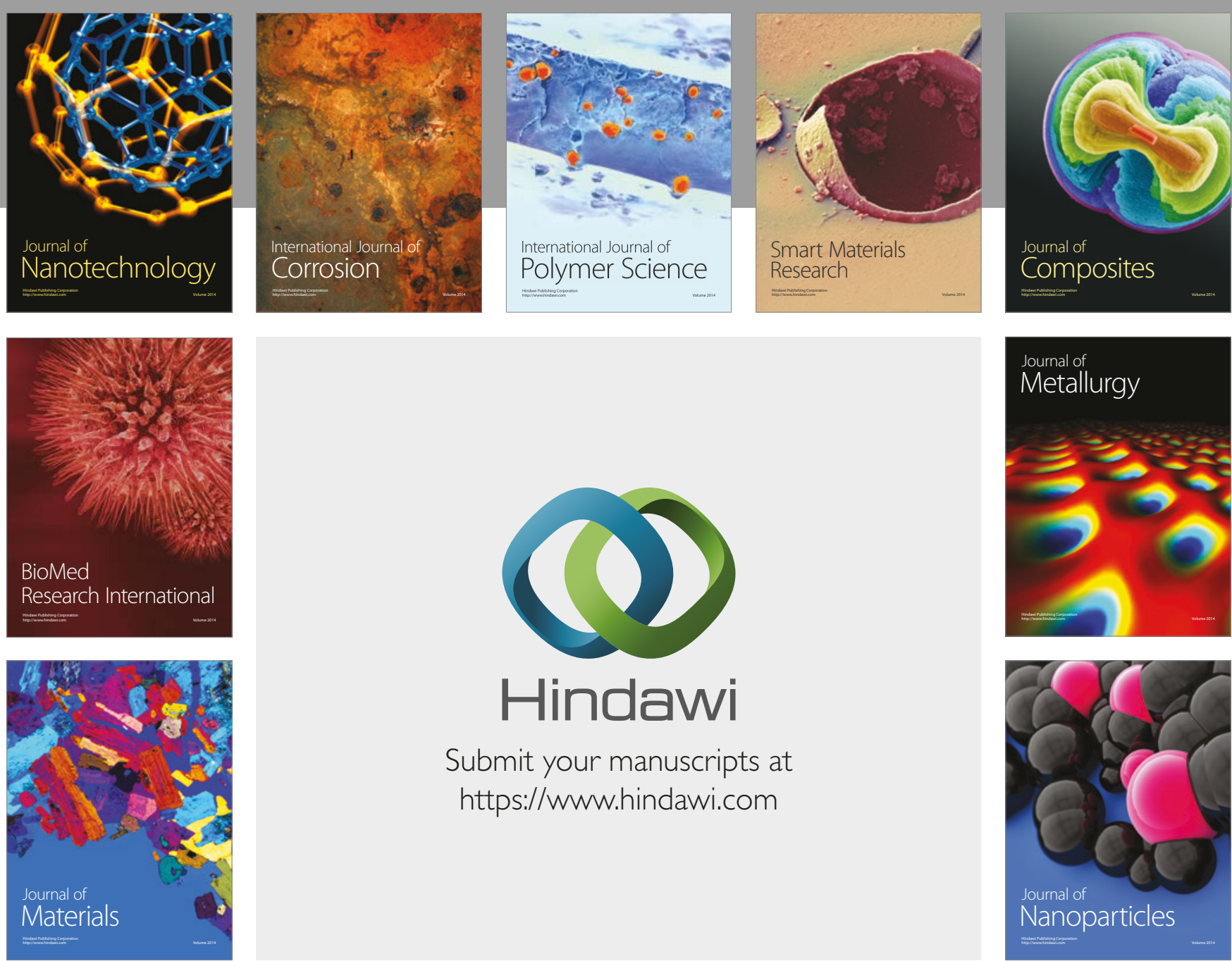

\section{Hindawi}

Submit your manuscripts at

https://www.hindawi.com
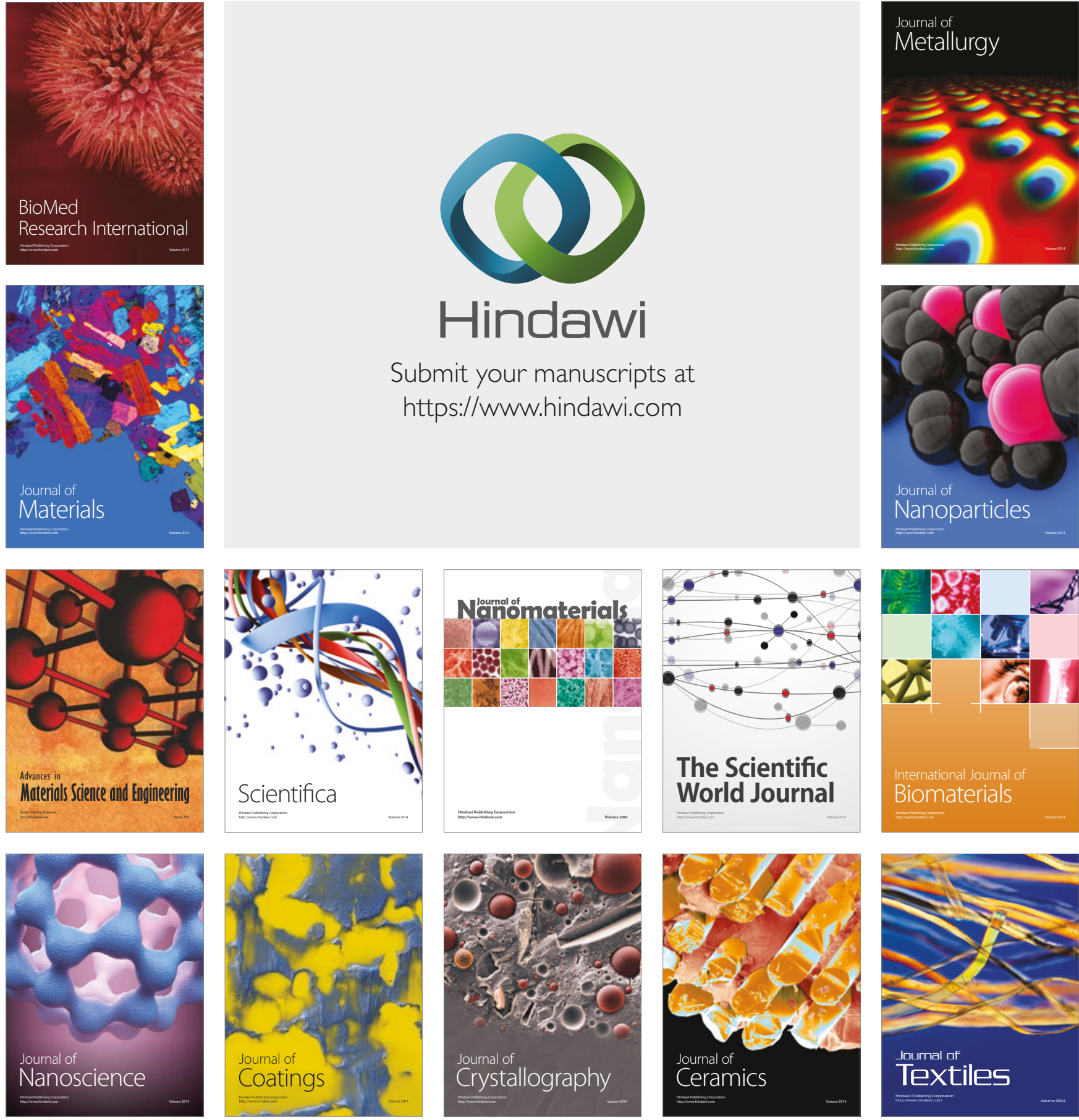

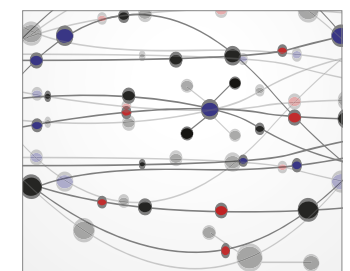

The Scientific World Journal
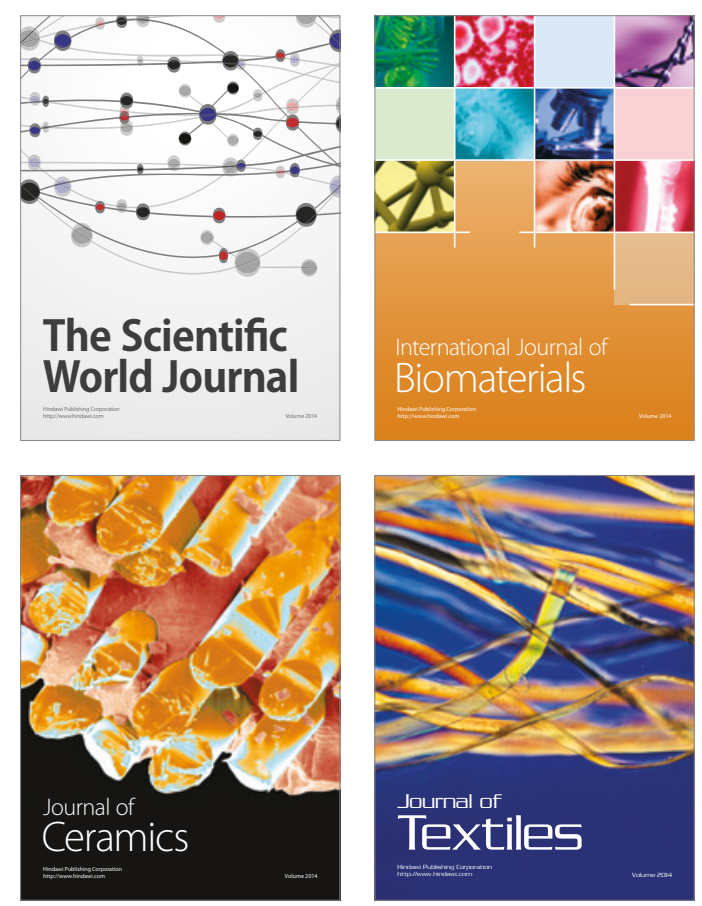